\title{
Stridor due to symptomatic Chiari II malformation: three cases of delayed diagnosis Eric Levey
}

Address: Keelty Center for Spina Bifida, Kennedy Krieger Institute, 707 North Broadway, Baltimore, MD 21205, USA

Email: Eric Levey - Levey@KennedyKrieger.org

from 52nd Annual Meeting of the Society for Research into Hydrocephalus and Spina Bifida

Providence, RI, USA. II-14 June 2008

Published: 3 February 2009

Cerebrospinal Fluid Research 2009, 6(SuppI I):SI8 doi:I0.II86/1743-8454-6-SI-SI8

This abstract is available from: http://www.cerebrospinalfluidresearch.com/content/6/SI/SI8

(c) 2009 Levey; licensee BioMed Central Ltd.

\section{Background}

Myelomeningocele is virtually always associated with Chiari II malformation of the brain. The Chiari malformation can be associated with a variety of symptoms including cranial nerve palsies, central apnea, quadriparesis, and cerebellar abnormalities. Vocal cord paresis is a known finding that can be associated with symptomatic Chiari malformation.

\section{Materials and methods}

This is a case series from a large, urban, academic medical center in the United States. In 2007, the author identified three infants with myelomeningocele (MMC) who presented with stridor as the first manifestation of hydrocephalus or symptomatic Chiari II malformation. The three charts were reviewed.

\section{Results \\ Case \#I}

E.M. was born with MMC, closed the day of birth. Discharged home from the NICU at 13 days of life with stable mild ventriculomegaly. Parents reported intermittent stridor starting at about 2-1/2 months of age and increasing in frequency and severity. After about 6 weeks, was evaluated by ENT and found to have vocal cord paresis. Referred to neurosurgery and had VP shunt placement followed one week later by Chiari decompression.

\section{Case \#2}

M.S. was born with MMC, closed the day after birth. Discharged home for the NICU at 7 days of age with stable moderate ventriculomegaly. Hospitalized at 1 month of age with stridor. Diagnosed with laryngomalacia and viral upper respiratory infection. Stridor persisted and VP shunt was placed about 1 month later. Stridor resolved.

\section{Case \#3}

M.T. was born with MMC, closed the day after birth. A VP shunt was placed at 11 days of age. Developed stridor at about 3 months of age. Was seen by ENT and diagnosed with larygomalacia. Had increasing reflux and feeding intolerance. Found to have chronic lung disease and admitted at 4 months of age. Had Nissen fundoplication and gastrostomy. At 6 months, had worsening stridor, requiring intubation. Had Chiari decompression. Discharged home 1 week later on room air without stridor.

\section{Conclusion}

Stridor due to vocal cord paresis can be seen as initial manifestation of hydrocephalus/symptomatic Chiari II malformation, but correct diagnosis can be delayed due to lack of familiarity of parents and pediatric providers, further delaying definitive treatment. 